\title{
Storying students' becomings into and through higher education
}

\author{
Karen Gravett ${ }^{\mathrm{a}}$ and Naomi E. Winstone ${ }^{\mathrm{a}}$ \\ a Department of Higher Education, University of Surrey, Guildford, Surrey, United Kingdom, \\ GU2 7XH k.gravett@surrey.ac.uk
}

\section{Keywords}

Transitions; story completion; higher education; rhizome; becoming; timescapes

\begin{abstract}
This article employs a new approach to understanding student transition. This area of theory and practice has developed huge global significance. However, transition as a concept is undertheorised, and a discourse that reiterates stereotypic narratives of students' normative and linear trajectories can be seen to permeate the field. Drawing on data collected using story completion methods, together with semi-structured interviews, we examine this stereotypic discourse that surrounds stories of transition. Our data suggest that this narrative exists in tension with a more nuanced picture: one that depicts the diversity, fluidity and complexity of students' lived experiences. In order to better understand these experiences we employ a theoretical approach that conceptualises transitions as troublesome, as rhizomatic, and as becoming. We argue that this approach offers the potential to look beyond normative narratives that surround student transition, and to celebrate students' becomings in a more rich and generative way.
\end{abstract}

\section{Introduction}

Transition has been explored within the literature for many years and today this area has become a hugely significant area of policy, research and practice. However, recently theorists have begun to critique how transition has been previously understood and subsequently enacted in policy and practice (e.g. Gale and Parker 2014; Taylor and Harris-Evans 2018; Gravett 2019a; Gravett, Kinchin and Winstone 2019). Indeed, it can be argued that much of the thinking which informs policy, research and practice in the field can be considered as falling within a normative and unquestioned paradigm of transition. Within this paradigm, students are often depicted as following homogeneous pathways that include the navigation of critical stages 
(induction; 'welcome' week; the 'first year experience') and the paradigm can be seen to be informed by an agenda where institutional concerns of success and retention are prioritised. This is problematic, as this narrative fails to fully acknowledge the complexity, fluidity and multiplicity of students' lived realities. Moreover, as Gale and Parker argue, transition related research and initiatives can be seen to be permeated by 'conceptual silences' where understandings of the very meaning of transition are not clearly articulated or subjected to critique and are instead based on taken-for-granted concepts regarding ideal student experiences $(2014,746-7)$.

As a result, such conceptions of transition have fostered an intense focus on short term, practical, strategies to promote success, for example: pre-entry, induction and welcome week initiatives, described evocatively by Quinn as a 'fetishization of certain time frames and activities' (2010, 123). In her recent work on doctoral education, Manathunga (2019) argues for a reconceptualisation of rigid doctoral 'timescapes' and presents the need for making space for individuals' epistemic, lived and eternal temporal rhythms. Manathunga contends that politics of higher education in Australia has become dominated by neoliberal agendas of efficiency, profitability and managerialism, altering the 'timescapes' of higher education, meaning that doctoral candidates and supervisors are subjected to increasing time pressures and required to produce a wide variety of outcomes in very short timeframes $(2019,1)$. This notion can also be applied to student transition. Within student transition too, the intense focus on fixed time frames and outcomes can also be seen to alter the 'timescapes' of higher education, presenting a view of time and of transition that may exclude individual lived temporal rhythms.

What is missing from these narratives then are the multiplicities of students' experiences: those stories that exist in the gaps and margins of a narrative, and that deviate from preconceived expectations and homogeneous, linear pathways. How, then, might we begin to understand the diversity of students' lived experiences? In order to attend to this question we put to work a theoretical approach that conceptualises transitions as troublesome, as rhizomatic, and as becoming (Gravett 2019a). Furthermore, we also employ a new methodological approach to research students' experiences as we examine how we can gather students' own narratives of transition using story completion methods. We were interested to explore: what will these 
stories tell us about students' understandings of transition and becoming within higher education, and how will these narratives compare to the pervasive grand-narratives of research, policy, practice?

\section{Transitions within the literature}

An exploration of the literature addressing this key issue highlights a pervasive narrative that can be seen to be underpinned by a number of taken for granted assumptions regarding educational transitions, students' experiences, and students' learning within higher education (see also Gravett, Kinchin and Winstone forthcoming; Gravett 2019a). These narratives include the recurring tropes of 'bridges' or 'gaps' (Leese 2012; Lowe and Cook 2003; Briggs, Clark and Hall 2012), alongside the notion that transition is a phase to be quickly settled and smoothed (Murtagh 2012; Yorke 2000). These constructs position students within a negative space: as vulnerable, as unprepared, and as in deficit. Also problematic is a narrative where transition is depicted as a structural 'process' to be managed, supported, and completed (Hultberg et al. 2008, 49; Hughes and Smail 2015, 467). Students are expected to follow linear transition journeys that involve discrete stages (induction; 'welcome week'; the 'first year experience'). Yet these narratives fail to acknowledge individuals' lived temporal rhythms, the ongoing nature of learning and development within higher education, and the ongoing nature of 'transition' itself.

However, recent work has begun to offer new perspectives within this often uncontested area. Taylor and Harris-Evans $(2018,1264)$ advocate 'doing transition anew' and ask: how can we better understand the complexity and individuality of students' experiences during 'transition'? Kahu and Nelson $(2018,58)$ argue that 'the transition metaphor, focusing on the first year, is limited because it depicts differences between students and institutions as both transient and temporal'. Further, Ecclestone asks us to question whether a 'pedagogy of the self erodes educational goals and practices in favour of being supported and managed through a seamless, endless set of comfortable transitions' (2007, 12). Likewise, Gale and Parker's $(2014,747)$ typology of student transition offers a powerful rethinking of previous assumptions surrounding transition and recommends that future research in the field be 'cognisant of students' lived reality, not just institutional and/or systemic interests'. Similarly, Winstone and 
Hulme (2019) offer new perspectives on conceptions of transitions that disrupt normative understandings and recommend that we find ways to engage with the uniqueness of student voices. Our article thus seeks to build on this growing shift towards 'doing transition anew' within the literature, and in particular to engage with a new framework for conceptualising transition (Gravett 2019a) that considers transitions as troublesome, as rhizomatic, and as becoming.

In this conceptual approach, Gravett responds to the 'conceptual silences' (Gale and Parker 2014) that exist within the field. Gravett applies the work of Meyer and Land (2005) and Deleuze and Guattari (1987), and particularly concepts of the 'rhizome' and 'becoming', to explore the irregularity and fluidity of students' experiences, and how we might employ concepts of troublesome knowledge and liminality to acknowledge the value of discomfort and struggle as a necessary part of learning. In A Thousand Plateaus, Deleuze and Guattari (1986) introduce the concept of the rhizome, based on the idea of a botanical rhizome. A rhizome can spread in multiple directions: it 'has no beginning or end; it is always in the middle, between things, interbeing, intermezzo' (ibid. 26). This concept thus presents the idea of transitions as ongoing, as based on multiplicities, singularities, and fluid connections, and destabilises linear understandings that look for homogeneous pathways with fixed turning and end points. Similarly, Deleuze and Guattari contend that 'a line of becoming has neither beginning nor end, departure nor arrival origin nor destination' (Deleuze and Guattari 1987, 342). Becomings are ongoing and continuous. Gravett thus suggests that through applying these key concepts of rhizome and becoming we can adopt 'a new approach to conceptualising transition', one that 'may be useful in enabling us to see the granularity and singularity of students' experiences, and that individuals' lived realities do not fit neatly into established linear grand-narratives of transition' (Gravett 2019a, 1).

\section{Method}

\section{Participants}

The purpose of this study was to surface the complexities of becoming a student, and to begin to examine and understand students' experiences during their first year at university, a period 
traditionally viewed as a time of transition. In order to do so, we carried out a longitudinal research study that took place at two institutions, institutions A and B. Participants were students in their first year of their degree and were interviewed at the beginning of their course (around November or December) and then again towards the end of their first year (around May / June). The study included eleven participants who came from across a range of disciplinary backgrounds. Participants also came from a range of social and cultural backgrounds including students who were first in their family to enter higher education, international students, Black and Minority Ethnic (BAME) students, and commuter students.

Two institutions were chosen in which to recruit participants in order to add depth to the study. One institution (institution A) is a traditional research-intensive institution, whilst the other (institution B) has a diverse profile including a high intake of BAME students, a high intake of students from state schools, and a higher than average intake of students who are the first in their family to attend higher education. A longitudinal approach was chosen in order to gain the opportunity to discuss with participants how their views and experiences had evolved over time, as well as to offer the opportunity to invite participants to create two stories and then for these to be compared.

\section{Story completion}

The research study applied a new method to transition research using a story completion method (Gravett 2019b; Clarke et al. 2017). Story completion is adaptable to a range of research questions and approaches. In this study, story completion was employed as a sensemaking exercise. We were interested in discovering what participants thought and wrote about transitions, learning and unlearning during university. On each occasion, participants were given a story stem (see appendices). The first story (completed in November/December) features a character named Alice who is settling in to university life. The second story (completed in May/June) features a character, Adam, who is reflecting back on his past year at university. Participants were then asked to continue the story. Participants were given specific guidelines about how to write the story. The story stems (included below) were written with the goal of achieving a balance between providing the participant with a meaningful and relatable context, and leaving enough space for students to play with the story and draw upon their own understandings and perceptions of the topic. A story completion method is highly 
flexible (Gravett 2019b). There are many considerations to think about when creating story stems in terms of the kinds of protagonists that the stories include, the contexts established, and what kinds of associations these decisions might result in for participants. In this instance, when creating the stems, we aimed to keep the stories fairly open, without providing too much detail about the characters' backgrounds. On reflection, gender neutral names for the protagonists would have perhaps been even more effective in keeping the stories open to interpretation.

\section{Story stem example - first story}

Alice is a new undergraduate student in her first year of University. She has been struggling to get to grips with University life. Lots of aspects of studying are not as she expected they would be, and are different to what she had previously been used to at college. Her personal tutor asks her how she is getting on and she tries to explain how she is feeling.

\section{Story stem example - second story}

Adam is a new undergraduate student coming towards the end of his first year of University. He looks back on his last year. What do you think he might have done or might have happened to him? How do you think he feels about learning and studying at University?

One of Adam's friends asks him how his first year has been. Please complete the story explaining what happens next.

The story completion method was chosen for a number of reasons. Firstly, story completion can enable participants to engage more readily and openly with the topic presented. As the students are writing a fictional story, involving a hypothetical scenario, they are not being asked directly about their feelings which they may feel unwilling or unable to discuss with the interviewer. Secondly, we were interested in surfacing the discourses that individuals draw upon to write. In story completion, the goal is not to look for the 'truth' of the respondents.

Rather: 'within a story-completion method, participants have to draw upon sense-making resources to tell a story, and thus story completion can be particularly useful for exploring assumptions and understandings about a particular topic' (Gravett 2019b, 21). 
Lastly, we wanted to employ story completion as a method as it affords research participants an unusual degree of autonomy over the research process. As participants author their own stories they are engaged in the research process in an active way and therefore the method can be potentially emancipatory for participants as they become active authors of the data. We felt that this and the pleasure of writing the stories would hopefully mean that the research was enjoyable to take part in for the students.

However, Clarke et al. (2017, 9) also write that 'story completion offers scope for methodological innovation:' and that 'qualitative researchers have only recently begun to fully explore the possibilities that SC offers'. Our approach thus sought to respond to this invitation for innovation. We therefore deviated from previous story completion approaches in that we decided to additionally include a semi-structured interview with participants to discuss their experiences of the writing of the story, and to consider how their own experiences contrasted or aligned with their fictional story character. The goal of this was to provide an opportunity for participants to reflect on the story completion method but also to examine the differences between the students' self-reported experiences of higher education, and the discourses that they used to inform the story writing. The initial story completion task then also served as a useful tool to relax participants and begin their thinking about the topic before the interviews commenced. Overall, in terms of detail and granularity, we sought to achieve what Gourlay (2015, 409) describes as a: 'fine-grained qualitative understanding of student practices'. Interestingly, Gourlay notes that:

In this respect, I would argue that it is incumbent on the field of higher education studies to investigate the nature of actual day-to-day student practices in particular those which are hidden, textual and private, in order to gain a fuller picture of forms of engagement which are under-researched, occluded from view $(2015,409-410)$.

Through the surfacing of discourses, tropes and perspectives surrounding transition via the story completion activities, together with the interviews, our research aimed to gain a fuller picture of students' experiences, particularly those that have previously been under-researched or occluded.

\section{Data analysis}


We employed an innovative approach to analysing these data that has not as yet been used for story completion research, where a traditional thematic analysis or discourse analysis is often employed (Clarke et al. 2017). Instead, we chose to employ a rhizomatic data analysis (see also Gravett 2019b) inspired by Deleuze and Guattari (1987), and subsequently Maclure (2010) and Taylor and Harris-Evans (2018). Rhizomes evoke the idea of multiplicities, singularities, and fluid connections, and offer a critique to ideas of linearity and of regularity. A rhizomatic analysis thus 'opens a way of working with data in its nuances, differences, singularities, contradictions and difficulties' (Taylor and Harris-Evans 2018, 1257).

Following Taylor and Harris-Evans, and Maclure, we thus actively looked for ways of working with data in its nuances, differences, and singularities. We used this approach to analyse data across the entire corpus of data including both sets of stories and interview transcripts. First, both researchers read through the transcripts and stories independently. Next, upon reading through both the stories and the transcripts we looked for data 'hotspots' that captured our interest: 'data fragments' that 'glimmer' and 'glow', 'gathering our attention' (Maclure 2010, 282). This reading process was subsequently followed by an iterative discussion of these data fragments between the two researchers. 'Within this approach, the researcher/s actively do not look to prioritise regularities within data. Rather, a rhizomatic analysis enabled us to retain those singularities and multiplicities within the data that we were most interested in examining' Gravett 2019b, 20). As a result, this approach contrasts with traditional analytical approaches that look for themes, regularities and patterns within data. Instead, a rhizomatic analytical approach enabled us to retain those singularities and multiplicities within the data that we were most interested in examining.

\section{Reflexivity}

Partly due to the researcher building a relationship with participants over time, and partly due to the personal nature of the research topic, the interviewer's presence played a significant part in relations within this study and therefore we devote some time to discussing this here. Indeed, one participant commented that participation in the study itself had offered a positive experience, a means to build relations with staff, and had helped them with the transition into and through university. As a result, this reflexivity needs to be acknowledged. However we do 
not see it as a shortcoming. On the contrary the power of our interactions with the area in which we were researching was that this positionality enabled a relationship of trust and openness to develop over time. As such, by using our knowledge openly and transparently to add value to the research, we believe that this position can be viewed as a valuable resource (Holliday 2002) that can be realised and capitalised upon (Holliday 2005, 305). An unexpected additional outcome was also the usefulness of this relationship as a transition intervention (as evidenced by the comment of the participant, above).

\section{Ethical issues}

Institutional ethical approval was granted for this study to take place at both participating institutions. All participants also provided informed consent for their participation. It was made clear that participants could withdraw at any time (and two participants subsequently did choose to withdraw from taking part in the second interview, due to personal reasons that were unrelated to the research process). Finally, in order to manage the subjectivity inherent within the research, to show 'rigour' (Holliday 2002), and to 'show the workings' (ibid., 48) our results were also externally validated via a member check with participants to ensure that they were in agreement with the findings. In the discussion below our student participants are each represented by pseudonyms.

\section{Findings and discussion}

The participants' stories were a rich resource. Often emotional and vivid in their imagery, they included evocative phrases such as: 'there were times when Adam definitely felt as though he was falling down a deep, dark, well' (Mena, second story) and 'she watches each student in her periphery; one with a stack of textbooks costing more than her rent' (Catherine, first story). As such, the participants engaged with the story completion task and often wrote full and interesting stories. It became apparent during analysis that the participants' stories often drew upon a repertoire of understandings that referenced normative and conventional discourses surrounding transition. For example the students in the stories are often depicted as in difficulty or vulnerable: 'she doesn't want to make an impression of the girl who cries' (Lucy, first story) and 'I just feel like I'm not supposed to be here' (Sophie, first story). In part this can be seen 
as understandable. The story stems established a certain context of students settling into university life and experiencing difficulties. However, what is particularly interesting is that, in contrast, the interview data is markedly more nuanced. Rather, within the interviews, our data suggest students' divergent, unique and individual experiences. Although often the participants discussed how they had drawn upon their own experiences for the stories, they also openly remarked on this disconnect between the stories and interviews, for example in this revealing comment: 'I'm not quite as helpless as I made Alice be' (Nyah, first interview). We now turn to explore these disconnects more fully, and to discuss the key hotspots that surfaced within our data.

\section{A 'new style of learning': unlearning and learning new approaches to studying}

Within this research study we sought to understand how the concept of unlearning might play a part within students' transitions into and through higher education. It became clear that the data depicted students' need to unlearn particular approaches to studying, for example ways of reading, note-taking and finding sources.

The work is enjoyable but it can be challenging for her to motivate herself... at school there would be obvious consequences for not doing homework (Mary, first story).

I think you're quite stuck in a certain way of learning when you leave school... by the time I was doing my second or third assignment I kind of clicked on and then it was a lot easier and it's become routine now. It's just what I do (Laura, second interview)

If you take everything down in lectures, you are never going to finish taking notes. You're going to be there for ever. And keeping up with what lecturers are saying as well...it's hearing the words and seeing stuff from the slides and managing to integrate both of those. I think that's the main thing that's come out of the new style of learning (Lucy, second interview)

The students spoke of dissonance between their existing conceptions of how to study and the 'new style of learning'. These students described their need to fundamentally change their epistemological approaches to understanding how to read and approach texts, how to note take, and how to develop their own voice. Once these skills were grasped it became a part of them: 'it's just what I do'. This highlighted that for many students, developing new approaches to 
studying can be considered a threshold concept (for example see Meyer and Land 2005) as students needed to grasp new ways of approaching learning and to unlearn pre-existing methods that had previously worked for them. Understandably, this was often uncomfortable; a culture shock: 'you're quite stuck in a certain way of learning'.

\section{'It's small things': students' individual and micro experiences of transition.}

It also became apparent within the data that this area of academic skills development was only a small and relatively superficial aspect of what transition signified to the students. Instead, for our participants, transition meant a myriad of different and individual micro experiences. These included relationships, emotions, social, affective, material and spatial elements, and reached far beyond the acquisition of study skills, the development of subject knowledge, or adaptation to institutional norms. Indeed, as Emily explains: 'the hardest part of Uni probably isn't the work. It's not the academic part of it at all' (Emily, first interview). For Mena, transition was described as being made easier by the contentment of living at home with her family and particularly her pet (Mena, second interview). For Jo, transition is 'oh, just silly things like doing a food shop and not taking a list and coming back and having nothing to cook with.' (Jo, second interview). For Sara, transition was described as the challenges of feeling like an outsider for not drinking: 'they can't expect me to act a certain way so I've become more of myself from the get-go' (Sara, first interview), and the importance of having her boyfriend to talk to as he attends a different university and is 'outside the bubble'. Catherine describes the challenges of navigating staff-student relations: 'I mean they say go and see your personal tutors, like that's your problem if you don't want to go and see them but it's still a scary thing' (Catherine, second interview). These comments from Imran clearly encapsulate the significance of these micro experiences:

It's just small things. Like everyone panicked in the first month and I know someone in front of me spent $£ 200$ on books and it's quite expensive and you're not going to be using these books at all (Imran, second interview).

Small things like complaining about a broken drawer handle in his student accommodation. All of this is part and parcel of adulting (Imran, second story).

For the students, then, transition encapsulated a huge wealth of unique and individual micro experiences that went far beyond their development of new approaches to 
studying. What was intensely important to one student was quite different to what mattered to another. This reminds us of Gourlay's argument for a: 'fine-grained qualitative understanding of student practices' 'in order to gain a fuller picture of forms of engagement which are under-researched, occluded from view' (Gourlay 2015, 409410). It also echoes Taylor and Harris-Evans' $(2018,1259)$ views that 'transition is a complex, sometimes confusing whirl of emotions, spaces, materialities, people, relationships, histories, affects, responses, demands and expectations.' For these students, transitions can be seen to be complex, individual, and rhizomatic.

\section{'You're constantly changing': fluidity and change within transition}

Our data also depicts students' transitions as ongoing and fluid. Both the students' stories and interviews suggested that transitions were non-linear, but instead were better understood as an ongoing series of becomings. While for some students they found their experiences to be positive at the start, by the latter interview their views had changed, for example: 'it's a slippery slope. You miss one lecture... and you never look back' (Nyah, second interview). The students clearly articulated their development as ongoing, fluid and non-linear, as evidenced by these quotes:

What I have felt for the last two, three years may change in the next two, three years. People change...I feel like in terms of my future self it was very beneficial to pick such abroad course (Mena, first interview).

You're constantly changing, you're constantly meeting new people (Laura, second interview).

This first year has been a rollercoaster (Simran, second story).

The reality of these rhizomatic becomings sit in contrast to linear narratives of increasing competence and adaptation. This narrative is described poignantly by Catherine in her first story: 'Every one of these people has their shit together, Alice thinks. Maybe they're second years. They always say you should know what you're doing by then.' However, in contrast, the students' experiences resonate more with postmodern and poststructural perspectives that suggest that 'the whole of life is a form of transition' (Ecclestone, Biesta and Hughes 2010, 6), and that 'we are always lost in transition, not just in the sense of moving from one task or context to another, but as a condition of our subjectivity.' (Quinn 2010, 123). These students' 
experiences also resonate with Manathunga's $(2019,1)$ critique of 'timescapes' that encourage 'assimilationist pedagogies'. Manathunga argues instead for 'making space for epistemic, lived and eternal temporal rhythms' $(2019,1)$, and there are clear parallels to be drawn here with the experiences of first year students, where the lived rhythms of learning do not fit neatly into 'assimilationist pedagogies'. Within this conception, a question for institutions thus exists in how to reconcile the fluidity and rhizomatic experiences of students with the conventional linear and modular institutional approaches to the acquisition of knowledge that may be driven by neoliberal agendas of efficiency and managerialism. As Manathunga $(2019,11)$ contends 'university managers and governments will need to acknowledge that universities are not only businesses'. A further challenge also exists in how institutions prepare students for transition as an ongoing aspect of life, and for transitions to continue into the workplace and beyond.

\section{'I definitely don't miss school': student agency and positive transitions}

As explained, our findings also evinced a disconnect between the normative depictions of students within the stories and students' divergent experiences that emerged within the interviews. Furthermore, often students described very positive experiences and attitudes within the interviews.

I definitely don't miss school...it's better to know that it depends on you how you write and what you choose to write on, which is awesome. (Simran, first interview)

I was ready to go up to the next level of self-study after college...it's very much you're on your own. I quite like that to be honest because you get to read around what interests you rather than what you're supposed to know.... I was definitely ready to move on (Lucy, first interview).

I was already quite independent when I came to Uni...because my mum, she's disabled, so I already do a lot of stuff at home for my brother' (Maria, first interview).

These comments offer a divergent view to how students are often depicted within contemporary debates regarding students' learning, where they are often described as lacking independence and requiring spoon-feeding (e.g. Smith 2008; Hanna et al. 2014). On the contrary, these students do not appear vulnerable or lacking in independence, and are instead more than ready for the challenges of learning within a new context. 
'It doesn't feel like I'm living the same experience': commuter students' experiences.

A further data hotspot within our results surrounded the students' discussions regarding commuting to university, both within the stories and the interviews. This was particularly pertinent to the participants from institution B where a higher proportion of students commuted. It emerged that this was a complex area. Again the stories referenced stereotypical views, for example of commuting as a negative aspect of university life: 'the commute was long and lonely' (Mena, first story). However, in the interviews, the students' relationship with commuting became more complex. When discussing her peers, Mena commented that: 'it doesn't feel like I'm living the same experience as they would, even though we go to the same uni' (Mena, first interview). However, Mena also commented on how commuting was good in aspects, because 'obviously my mum would do the laundry and stuff like that' (first interview), and in the second interview Mena commented on the comfort of being able to return home to her family and pets as being one of the most important factors in being able to settle into university. In contrast, Nyah spoke about how most of her friends commuted so this was the norm (first interview), and how they would use this time positively to watch lecture recordings and complete their study notes (first interview). She then commented that 'some people I know actually live on campus which is better but then they're like I've got no money' (first interview). For us this exposed the markedly different experiences of students who are often no longer experiencing university as a traditional departure from home to adulthood; for Nyah the few people she knew who did live on campus were considered the exception. However, it also indicated how different the experiences were for students, even from within a 'commuter sub-group.' For these participants commuting meant many things: catching up on note-taking, being taken care of by family, being both an insider, and an outsider.

Troublesome transitions: 'It is just a matter of time until all the pieces of the puzzle fall into the right place. You have to just keep looking for the right pieces'

A further significant hotspot within the data was the students' discussion, within both the stories and the interviews, of the difficult and troublesome nature of learning and development at university. Again this meant more than simply the development of study skills but signified the difficulties in academic, social and relationship development. In general, the students 
suggested that they fully recognised that transitioning into and through university can be uncomfortable and can take time.

Everything took time and effort (Mena, second story).

Alice was positive and knows that everything will eventually fall into place... It is just a matter of time until all the pieces of the puzzle fall into the right place. You have to just keep looking for the right pieces (Imran, first story).

Eventually you will find your place (Imran, second interview).

These comments and extracts from the stories support the notion of transitions as troublesome, (Gravett 2019a), echoing the processes described by Meyer and Land (2005) where the acquisition of new and difficult knowledge can be uncomfortable, as students struggle to cross the threshold to their new, transformed state of understanding. Meyer and Land employ the concept of liminality (see also Turner 1969) which describes a transitional space/time of indeterminancy, and emotional destabilization. This is considered to be a time in which individuals may experience difficulty and anxiety, particularly in relation to notions of being 'stuck', and interestingly being 'stuck' was another phrase that emerged within the data (for example Laura, second interview, who describes being 'stuck in a certain way of learning'). A conception of transition as inherently troublesome and uncomfortable sits in direct contrast to notions of seeking smooth, comfortable, transitions, and interventions designed to ease and settle students into higher education. Rather, this viewpoint offers the potential to see the value of emotional destabilisation and indeterminacy, and the possibilities that risk, uncertainty and change can create, and as transition as a necessary phase of change and becoming. As we have seen, it is not the case that all students will necessarily experience discomfort. An approach to understanding transitions that recognises the normality and value of learning experiences that may be difficult may be a useful direction for developing students' agency and moving away from an approach that foregrounds students' vulnerability in the face of change.

\section{Implications for supporting and doing transition}

Our data have been rich enough to enable us to suggest a number of important implications for theorising and doing transitions. While the unlearning and learning of new approaches to 
studying at university came through within our study, it was also clear that this was but a fragment of what was significant to our students about the concept of transition. Instead, for our participants, transitions signified a breadth of micro-experiences that were often unique and singular. Even within our group of commuter student participants, experiences were complex, and were understood and articulated quite differently. Further, students described their experiences as often necessarily uncomfortable and troublesome. This was viewed as a necessary part of learning growth and becoming a student. Our students also shared their positive experiences of university and readiness for higher education, undermining deficit approaches that emphasise students' gaps, vulnerabilities and weaknesses. We contend, then, that transitions may be more helpfully understood as rhizomatic: as divergent experiences that do not follow a linear or set pathway, and that go beyond 'assimilationist pedagogies' (Manathunga 2019, 1). Rather than transition signifying a neat process where skills are acquired and students follow a linear pathway into and through university, transition changes with individual context, and can be better understood as students' perpetual and ongoing becomings.

Institutions may thus wish to reorientate their approaches away from supporting students to 'manage' the transition process, towards sharing an understanding of the positive aspects of the challenges and difficulties that may be inherent within a troublesome and liminal learning space. Moving forward, these findings may encourage institutions to examine new ways of doing and conceptualising transition that value the diversity and fluidity of students' experiences, that celebrate what students bring with them into higher education, and that revisit and question taken-for-granted 'timescapes' of higher education (Manathunga 2019). This study also highlighted to us the value in adopting a novel, story completion method, combined with a follow up interview, as well as enabling us to explore the merits of adopting an innovative approach to data analysis. Notably, the longitudinal nature of this study meant that the research also worked as an intervention, as an unexpected outcome was participants' enjoyment of the research process and comments on the benefit of taking part in the study in terms of developing student-staff relations and students having someone to talk to about their experiences.

\section{Conclusion}


This research study employed a new theoretical framework for understanding transition that deviates from traditional narratives and understandings of students' experiences as they begin higher education, and instead conceptualises transitions as troublesome, as rhizomatic, and as becoming (Gravett 2019a). Additionally, we also employed an innovative approach for collecting data via the use of a story completion method combined with follow up interviews with participants over a longitudinal period. Lastly, we also engaged with a new approach to data analysis that aimed to retain the focus on the singularity and irregularity of students' experiences. Through the use of these novel approaches, we sought to address the question of how can we understand the complexities of becoming a student; how can we retell the stories of transition? Our data portrays tensions between the stories, narratives and linear 'timescapes' that surround traditional conceptualisations of student transition, and the fine-grained, messy, nuanced, constantly changing, becomings of students' lived experiences. The implications of such a reconceptualization offers new potential for a sectoral rethinking of our approaches to theorising and doing transition, as well as raising new questions regarding our understanding of students' experiences of higher education. Key implications will be a need for institutions to offer support beyond the initial stage conventionally termed 'transition', as well as to seek to depart from initiatives or approaches that construct students as experiencing a homogeneous 'student experience', or as experiencing a transition period that should necessarily be managed, smoothed and eased. Rather, considering how we can share an understanding of the inevitable challenges and difficulties inherent within learning, and the ongoing nature of change and becoming may be more generative. Ultimately, we contend that reconceptualising transition as troublesome, as rhizomatic and as becoming enables us to better understand the diversity, fluidity and richness of students' experiences, and can also offer institutions new ways of supporting students' learning and development.

\section{References}

Clarke, V.; Hayfield, N.; Moller, N. and Tischner, I. (2017). “Once Upon A Time...: Story Completion Methods". In: Collecting Qualitative Data: A Practical Guide to Textual, Media and Virtual Techniques, edited by V. Braun, V. Clarke, and D. Gray. Cambridge: Cambridge University Press.

Deleuze, G and F. Guattari. 1987. A Thousand Plateaus: Capitalism and Schizophrenia. London Continuum. 
Ecclestone, K., 2007. "Lost and Found in Transition: The Implications of 'Identity', 'Agency' and 'Structure' for Educational Goals and Practices". Keynote paper presented at Researching Transitions in Lifelong Learning Conference, University of Stirling, June 22-24.

Ecclestone, K., G. Biesta, and M. Hughes. 2010. "Transitions in the Lifecourse: The Role of Identity, Agency and Structure". In Transitions and Learning Through the Lifecourse, edited by K. Ecclestone, G. Biesta, and M. Hughes, 1-15. Abingdon: Routledge.

Gale, T. and S. Parker. 2014. "Navigating Change: A Typology of Student Transition in Higher Education." Studies in Higher Education 39 (5): 734-753. https://doi.org/10.1080/03075079.2012.721351

Gourlay, L. 2015. "Student Engagement and the Tyranny of Participation." Teaching in Higher Education 20(4): 402-411. https://doi.org/10.1080/13562517.2015.1020784

Gravett, K. 2019a. "Troubling Transitions and Celebrating Becomings: From Pathway to Rhizome".

Gravett, K. 2019b. "Story Completion: Storying as a Method of Meaning Making and Discursive Discovery." International Journal of Qualitative Methods.

Gravett, K., Kinchin, I. M., and Winstone, N. E. Forthcoming. "Frailty in Transition? Troubling the Norms, Boundaries and Limitations of Transition Theory and Practice."

Hanna, L., M. Hall, P. Smyth, and S. Daly. 2014. "“I miss being spoon-fed'. A Comparison of Transition From School to University Education From the Perspective of Undergraduate Pharmacy Students". Pharmacy Education 14 (1): 37 - 43.

Holliday, A. 2002. Doing and writing qualitative research. London: SAGE.

Holliday, A. 2005. "How is it Possible to Write?" Journal of Language, Identity and Education. 4:4: 304-309 https://doi.org/10.1207/s15327701jlie0404_6

Hughes, G. and O. Smail. 2015. "Which Aspects of University Life are Most and Least Helpful in the Transition to HE? A Qualitative Snapshot of Student Perceptions." Journal of Further and Higher Education 39 (4): 466https://doi.org/10.1080/0309877X.2014.971109"

Hultberg, J., K. Plos, G. D. Hendry and K. I. Kjellgren. 2008. "Scaffolding Students' Transition to Higher Education: Parallel Introductory Courses For Students and Teachers." Journal of Further and Higher Education 32 (1): 47-57 https://doi.org/10.1080/03098770701781440

Kahu, E. and Nelson, K. 2018. "Student Engagement in the Educational Interface: Understanding the Mechanisms of Student Success." Higher Education Research and Development 37 (1): 58-71 https://doi.org/10.1080/07294360.2017.1344197

Leese, M. 2010. "Bridging the Gap: Supporting Student Transitions Into Higher Education." Journal of Further and Higher Education 34 (2): 239-251. https://doi.org/10.1080/03098771003695494 
Lowe, H. and A. Cook. 2003. "Mind the Gap: Are Students Prepared For Higher Education?" Journal of Further and Higher Education 27 (1), 53-76.

https://doi.org/10.1080/03098770305629

Maclure, M. 2010. “The Offence of Theory.” Journal of Education Policy 25 (2): 277-286.

Manathunga, C. 2019. “"Timescapes' in Doctoral Education: The Politics of Temporal Equity in Higher Education." Higher Education Research and Development.

https://doi.org/10.1080/07294360.2019.1629880

Meyer, J.H.F. and R. Land. 2005. "Threshold Concepts and Troublesome Knowledge (2):

Epistemological Considerations and a Conceptual Framework for Learning and Teaching. Higher Education 49 (3): 373-388.

Murtagh, L. 2012. "Enhancing Preparation for Higher Education”. Practitioner Research in Higher Education 6 (1): 31-39.

Quinn, J. 2010. "Rethinking 'Failed Transitions' to Higher Education”. In Transitions and Learning Through the Lifecourse, edited by K. Ecclestone, G. Biesta and M. Hughes, 118-129. London: Routledge.

Smith, H. 2008. "Spoon-Feeding: Or How I Learned to Stop Worrying and Love the Mess". Teaching in Higher Education 13: 715-718.

Taylor, C. A. and J. Harris-Evans. 2018. "Reconceptualising Transition to Higher Education with Deleuze and Guattari." Studies in Higher Education 43 (7): 1254-1267. https://doi.org/10.1080/03075079.2016.1242567

Turner, V. 1969. The Ritual Process: Structure and Anti-structure. London: Routledge.

Winstone, N. E. and J. Hulme . 2019. 'Duck to Water', or 'Fish Out of Water'? Diversity in the Experience of Negotiating the Transition to University" in Engaging Student Voices in Higher Education: Diverse Perspectives and Expectations in Partnership, edited by S. Lygo-Baker, I. Kinchin, and N. Winstone. London: Palgrave Macmillan.

Yorke, M. 2000. "Smoothing the Transition Into Higher Education: What Can Be Learned from Student Non-Completion." Journal of Institutional Research (9): 35-47.

\section{Acknowledgements}

This research was supported by an Association for Learning Development in Higher Education research grant to the first author.

We would particularly like to thank Martin Beeson for his help with the organisation of the data collection for this research study. 